\title{
A brief review of the histopathology of proliferative vitreoretinopathy (PVR)
}

\author{
Hardeep Singh Mudhar ${ }^{1}$
}

Received: 25 October 2019 / Accepted: 28 October 2019 / Published online: 2 December 2019

(c) The Royal College of Ophthalmologists 2019

\begin{abstract}
Proliferative vitreoretinopathy (PVR) is thought to represent an exaggerated and protracted scarring process following rhegmatogenous retinal detachment (RD) and following RD surgery. Following detachment, a combination of retinal ischaemia, inflammation and cell proliferation lead to the formation of tractional membranes on the epiretinal and subretinal surfaces and to marked gliosis within the retina that leads to retinal shortening. Both of these factors convert a rhegmatogenous RD into a tractional one are a major feature of RD surgery failure. The major cell types that are involved in PVR are retinal pigment epithelium (RPE), glial cells (principally Muller cells) and inflammatory cells (macrophages and lymphocytes). These cells interact with numerous growth factors and cytokines derived from the breakdown of the blood-retinal barrier and from vitreous contact that trigger a cascade of cellular processes, such as epithelial-mesenchymal transition (EMT), cell migration, chemotaxis, proliferation, elaboration of basement membrane and collagen and cellular contraction, that lead to overt retinal pathology. This review covers the histopathology of PVR and touches upon the cellular processes involved in the pathogenesis of PVR.
\end{abstract}

\section{Introduction}

Proliferative vitreoretinopathy (PVR) is a term that was originally used in a seminal paper published by Retina Society Terminology Committee in 1983 with further revisions in 1989 by the Silicone Study Group [1, 2]. It is an intraocular scarring process that complicates up to $10 \%$ of rhegmatogenous retinal detachment (RD) cases and is one of the main factors that lead to failed RD surgery [3, 4]. It comprises the production of epiretinal and subretinal fibrocellular membranes that contract and convert a rhegmatogenous RD into a tractional RD. This brief review will cover the histopathology of subretinal, intraretinal and epiretinal PVR and will briefly discuss what is currently known about the cell types involved in this scarring process and will discuss salient aspects of pathogenesis.

Hardeep Singh Mudhar

hardeep.mudhar@nhs.net

1 National Specialist Ophthalmic Pathology Service (NSOPS), Department of Histopathlogy, E-Floor, Royal Hallamshire Hospital, Sheffield S10 2JF, UK

\section{Histopathology of PVR}

\section{Epiretinal PVR}

Figure 1a, b illustrates very well, the typical histological appearance of epiretinal PVR. It comprises a band of fairly dense collagen (Fig. 1a) within, which is embedded spindle cells (Fig. 1b). This fibrocellular membrane has contractile activity and distorts the inner limiting membrane of the retina, which becomes concertinaed (Fig. 1c). Immunohistochemistry clearly demonstrates that most of the spindle cells are positive for Cytokeratin 7 (CK7,Fig. 1d). This indicates that these cells are transdifferentiated retinal pigment epithelial (RPE) cells and form the bulk of the cellular population in epiretinal PVR [5-8]. Other cell types that are present include myofibroblasts that express alpha-smooth muscle actin (Fig. 1e) that impart contractile properties to the fibrocellular membrane, GFAP positive glial cells (astrocytes Fig. 1f) and some CD68-positive macrophages (not shown).

\section{Subretinal PVR}

Figure $1 \mathrm{~g}$ shows a fairly typical appearance of subretinal PVR. The classical appearance is that of bands of basement 


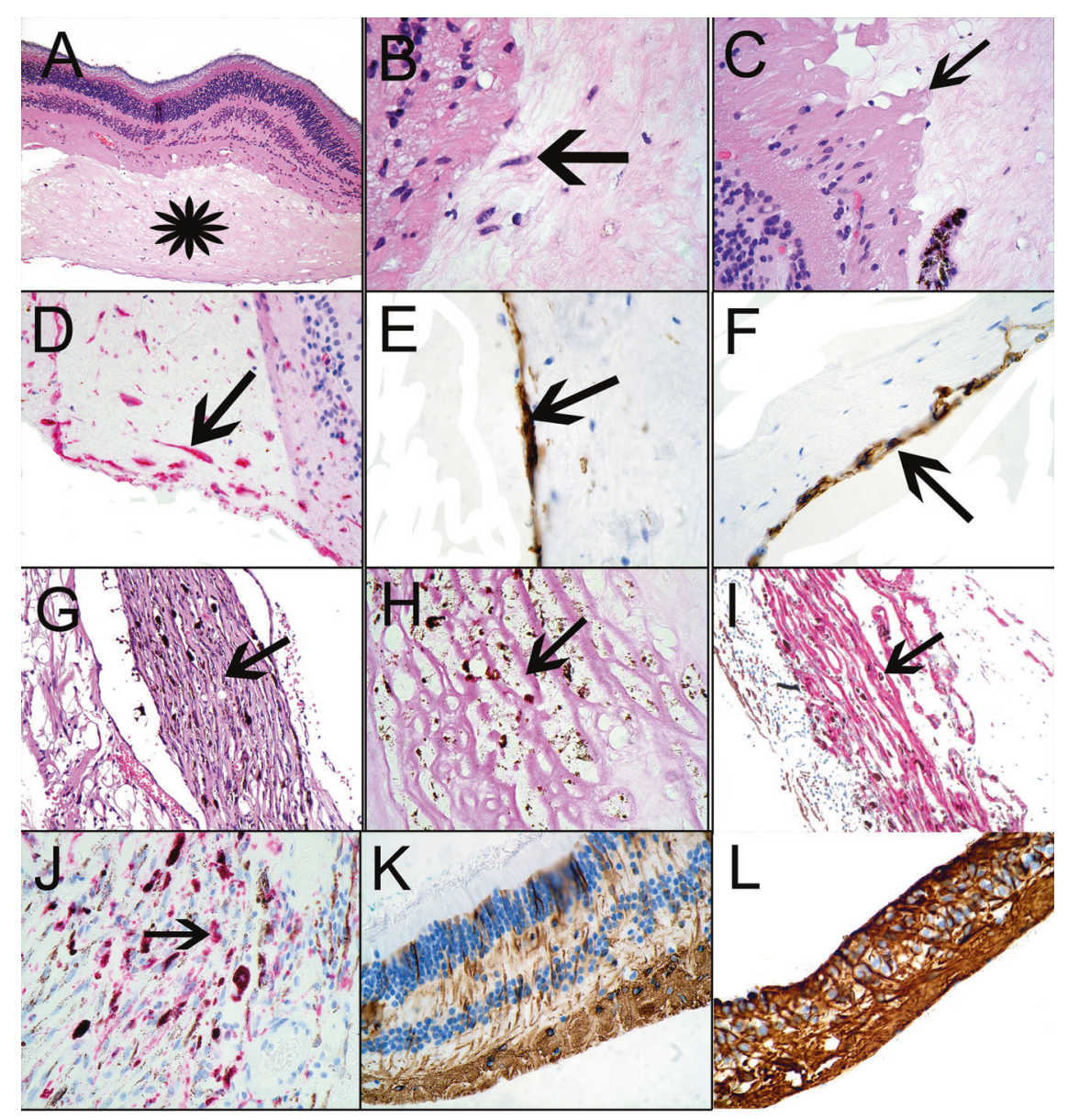

Fig. 1 a Haematoxylin \& Eosin (H\&E) stained section of retina. The asterisk indicates a fibrocellular membrane of PVR. b H\&E higher power image of plate A showing spindle cells (arrow) in the collagenous stroma of the PVR membrane. $\mathbf{c} H \& E$ showing the tractional effects of the PVR membrane. The arrow shows a concertinaed retinal inner limiting membrane. d Cytokeratin 7 immunohistochemistry showing that the spindle cells in the PVR membrane are positive (red $=$ positive) indicating that they are transdifferentiated retinal pigment epithelial cells (RPE-arrow). e Smooth muscle actin (SMA) immunohistochemistry showing positivity (brown = positive) of myofibroblasts in the PVR membrane (arrow). f Glial Fibrillary Acidic Protein (GFAP) immunohistochemistry showing glial cells in the PVR membrane (arrow). g H\&E showing typical subretinal PVR, with bands of pink basement membrane surrounded by pigmented RPE cells. h Periodic Acid Schiffs (PAS) stain showing the basement membrane rich (arrow) scaffold of subretinal PVR. i Cytokeratin 7 immunohistochemistry showing that RPE in the subretinal PVR membrane are positive (red = positive-arrow). j CD68 immunohistochemistry showing positivity $(\mathrm{red}=$ positive $)$ of macrophages (arrow). k GFAP immunohistochemistry of a relatively preserved stretch of retina showing positivity (brown $=$ positive) within the optic fibre layer below and streaks of positivity at right angles to the optic fibre layer, within the Muller cells. The blue dots are retinal neurons. I GFAP immunohistochemistry within a detached retina, showing panretinal positivity (brown $=$ positive), associated with loss of neuronal bulk. This is intraretinal PVR (gliosis)

\section{Intraretinal PVR}

type material that can be positive for Periodic Acid Schiffs stain (PAS) (Fig. 1g, h), around which are wrapped, tubes of RPE cells that express CK7 (Fig. 1i). Admixed with these cells are smooth muscle actin-positive myofibroblasts (not shown) and CD68-positive macrophages (Fig. 1j). These membranes form subretinal bands that impede retinal reattachment. They can also contract due to the presence of the myofibroblastic population [9-12]. In some cases, Muller glial cells migrate to the subretinal location to constitute the cellular mix. Another type of subretinal membrane comprises diffuse sheets of predominantly migrating Muller cells and is associated with less retinal morbidity [12].
This process comprises a gliosis that involves the Muller cells. This is due to hypertrophy and hyperplasia of Muller cells that lead to the process of retinal shortening and distortion that renders the retina difficult to flatten surgically [13-16]. Figure 1k illustrates a juxtaposition of fairly normal looking retina with one that is affected by intraretinal PVR (Fig. 11). The latter shows dense GFAP brown staining that indicates the glial cell pathology, in the context of extensive retinal neuronal cell loss. 


\section{Cell types involved in PVR}

It has been shown repeatedly from animal models and human retina biopsies that the main cellular constituent of PVR is the RPE [17]. Under normal circumstances, quiescent RPE sits on Bruch's membrane with a very low turnover rate. The latter is due to contact inhibitory influences $[18,19]$. When a rhegmatogenous RD occurs, there is damage to the blood-retinal barrier. This exposes the quiescent RPE to vitreous and blood-derived cytokines and growth factors that cause the RPE cells to initially detach from Bruch's membrane $[18,19]$. The RPE cells, under the influence of these cytokines and growth factors undergo a critical process called epithelial-mesenchymal transition (EMT), which converts a static polarised epithelial cell into a proliferative migratory spindle cell [18]. The latter elaborates basement membrane and collagen. These transdifferentiated spindle cells can migrate along the subretinal plane and assume an epiretinal location by migrating through retinal breaks, leading to the pathology illustrated in Fig. 1.

In rhegmatogenous $\mathrm{RD}$, ischaemia is present within the detached retina, leading to neuronal cell death. The space left by this becomes occupied by Muller cells that undergo hypertrophy and hyperplasia (gliosis) $[13-16,20]$ The gliosis appears to be a double-edged sword as on one hand, it is thought to be offer protection to further neuronal loss, but on the other hand, the Muller cells can release cytokines that lead to further cell loss [21]. The Muller cells are a rich source of cytokines that contribute to processes, such as cell proliferation, cell migration, chemo-attraction inflammation and fibrosis.

Macrophages occupy the subretinal space and vitreous after rhegmatogenous RD and are present in subretinal and epiretinal PVR. They are a rich source of cytokines that can mediate a variety of cellular processes similar to the cytokines released by Muller glial cells [22].

\section{Cytokines and molecular mechanisms involved in PVR pathogenesis}

One of the key steps in PVR is RPE EMT. Under normal resting conditions, the RPE cells are bound together by desmosomes and adherens junctions and attached to Bruch's membrane by hemidesmosomes. The cells express proteins, such as E-cadherin, epithelial cell adhesion molecule, occludins, claudins that all go to maintaining cellular polarity in RPE. In response to RD, exposure to vitreous and plasma products and inflammatory cytokines, the RPE cells undergo EMT, characterised by the expression of transcription factors (such as TWIST, SNAIL and ZEB) that activate various genes ( $\mathrm{N}$-cadherin, vimentin, beta 1 and 3 integrins, matrix metalloproteinases) that induce a mesenchymal state and repress the genes that are involved in epithelial polarity. The mesenchymal state confers the RPE cells with motility and invasive properties [23].

TGF-beta is present in high concentrations in eyes with PVR (there are three isoforms, TGF-Beta 1,2 and 3) and induces EMT and type I collagen and extracellular matrix production in RPE cells via the Smad intracellular signalling cascade. It is also involved in contraction of epiretinal PVR invoking macrophages and RPE-derived TGF-Beta 2, which induces myofibroblast differentiation from fibroblasts [24-30].

Some studies have shown an association between platelet-derived growth factor (PDGF) and the development of PVR. PDGF is a dimeric growth factor with many isoforms (PDGF-AA, AB, BB, CC, DD) that bind to its receptor causing dimerisation. The receptor subunits can be $\alpha \alpha, \alpha \beta$ or $\beta \beta$. Analysis of PVR membranes from humans has shown high expression of the ligand and receptors in RPE cells and Muller cells and acts as a mitogen for these cells as well as promoting migration and cellular contraction [31-35].

Tumour necrosis alpha has been implicated in PVR by the identification of genetic polymorphism of the TNF locus that predisposes some to PVR development [36].

Several chemokines are implicated in PVR including IL6, IFN-gamma. IL-6 is derived from macrophages and $\mathrm{T}$ cells and leads to proliferation of fibroblasts (and collagen synthesis) and glial cells. High levels of IL-6 have been identified in the vitreous of eyeballs exhibiting PVR $[37,38]$. IFN-gamma is also elevated in globes affected by PVR and activates macrophages [28, 39]. Other intracellular signalling pathways thought to be involved in the pathogenesis of PVR include the Jagged/Notch pathway and Wnt/ $\beta$-catenin signalling pathway [39]. Components of the Jagged/Notch pathway increase in RPE cells undergoing EMT from TGF- $\beta$ stimulation [39]. The $W n t / \beta$-catenin signalling pathway is also implicated in aspects of EMT [39].

\section{Summary}

An interplay of retinal ischaemia, inflammation and cell proliferation all conspire to lead to PVR. The main cell types implicated are RPE, glial cells and inflammatory cells. RPE cells undergo EMT that leads to their proliferation and migration, followed by the production of contractile fibrocellular membranes at epiretinal and subretinal locations. Intraretinal Muller cell gliosis consequent to ischaemia induced neuronal loss leads to intraretinal PVR and retinal shortening. A combination of the RPE/fibrocellular membrane pathology and the intraretinal PVR Muller cell 
alterations results in a retina that is difficult to flatten. Numerous cytokines, growth factors and signalling cascades orchestrate the interactions between the various cell types implicated in PVR and trigger EMT, cell migration, chemotaxis, proliferation, extracellular matrix deposition and collagen production. A detailed understanding of these pathways should permit novel strategies to overcome this dreaded complication of rhegmatogenous $\mathrm{RD}$ and $\mathrm{RD}$ surgery.

\section{Compliance with ethical standards}

Conflict of interest The author declares that they have no conflict of interest.

Publisher's note Springer Nature remains neutral with regard to jurisdictional claims in published maps and institutional affiliations.

\section{References}

1. The classification of retinal detachment with proliferative vitreoretinopathy. Ophthalmology. 1983;90:121-5. PMID: 6856248. https://doi.org/10.1016/s0161-6420(83)34588-7.

2. Lean JS, Stern WH, Irvine AR, Azen SP. Classification of proliferative vitreoretinopathy used in the silicone study. The Silicone Study Group. Ophthalmology. 1989;96:765-71.

3. Pastor JC, Fernandez I, Rodriguez de la Rua E, Coco R, SanabriaRuiz Colmenares MR, et al. Surgical outcomes for primary rhegmatogenous retinal detachments in phakic and pseudophakic patients: the retina 1 project report $2 . \mathrm{Br} \mathrm{J}$ Ophthalmol. 2008;92:378-82.

4. Pennock S, Haddock LJ, Eliott D, Mukai S, Kazlauskas A. Is neutralizing vitreal growth factors a viable strategy to prevent proliferative vitreoretinopathy? Prog Retin Eye Res. 2014;40:16-34.

5. Kampik A, Kenyon KR, Michels RG, Green WR, de la Cruz ZC. Epiretinal and vitreous membranes. Comparative study of 56 cases. Arch Ophthalmol. 1981;99:1445-54.

6. Hiscott PS, Grierson I, Hitchins CA, Rahi AH, McLeod D. Epiretinal membranes in vitro. Trans Ophthalmol Soc U K. 1983;103:89-102.

7. Hiscott PS, Grierson I, McLeod D. Retinal pigment epithelial cells in epiretinal membranes: an immunohistochemical study. $\mathrm{Br} \mathbf{J}$ Ophthalmol. 1984;68:708-15.

8. Jerdan JA, Pepose JS, Michels RG, Hayashi H, de Bustros S, Sebag M, et al. Proliferative vitreoretinopathy membranes. An immunohistochemical study. Ophthalmology. 1989;96:801-10.

9. Hiscott P, Hagan S, Heathcote L, Sheridan CM, Groenewald CP, Grierson I, et al. Pathobiology of epiretinal and subretinal membranes: possible roles for the matricellular proteins thrombospondin 1 and osteonectin (SPARC). Eye. 2002;16:393-403.

10. Trese MT, Chandler DB, Machemer R. Subretinal strands: ultrastructural features. Graefes Arch Clin Exp Ophthalmol. 1985;223: 35-40.

11. Wilkes SR, Mansour AM, Green WR. Proliferative vitreoretinopathy. Histopathology of retroretinal membranes. Retina. 1987;7:94-101.

12. Sternberg P Jr, Machemer R. Subretinal proliferation. Am J Ophthalmol. 1984;98:456-62.

13. Garweg JG, Tappeiner C, Halberstadt M. Pathophysiology of proliferative vitreoretinopathy in retinal detachment. Surv Ophthalmol. 2013;58:321-9.
14. Pinon RM, Pastor JC, Saornil MA, Goldaracena MB, Layana AG, Gayoso MJ, et al. Intravitreal and subretinal proliferation induced by plateletrich plasma injection in rabbits. Curr Eye Res. 1992;11:1047-55.

15. Pastor JC, Rodriguez de la Rua E, Martin F, Mayo-Iscar A, de la Fuente MA, Coco R, et al. Retinal shortening: the most severe form of proliferative vitreoretinopathy (PVR). Arch la Soc Espanola Oftalmol. 2003;78:653-7.

16. Pastor JC, Mendez MC, de la Fuente MA, Coco RM, GarciaArumi J, Rodriguez de la Rua E, et al. Intraretinal immunohistochemistry findings in proliferative vitreoretinopathy with retinal shortening. Ophthalmic Res. 2006;38:193-200.

17. Machemer R, van Horn D, Aaberg TM. Pigment epithelial proliferation in human retinal detachment with massive periretinal proliferation. Am J Ophthalmol. 1978;85:181-91.

18. Chiba C. The retinal pigment epithelium: an important player of retinal disorders and regeneration. Exp Eye Res. 2014;123:107-14.

19. Chen HJ, Ma ZZ. N-cadherin expression in a rat model of retinal detachment and reattachment. Investig Ophthalmol Vis Sci. 2007;48:1832-8.

20. Wickham L, Charteris DG. Glial cell changes of the human retina in proliferative vitreoretinopathy. Dev Ophthalmol. 2009;44:37-45.

21. Fischer AJ, Zelinka C, Milani-Nejad N. Reactive retinal microglia, neuronal survival, and the formation of retinal folds and detachments. Glia. 2015;63:313-27.

22. Eastlake K, Banerjee PJ, Angbohang A, Charteris DG, Khaw PT, Limb GA. Müller glia as an important source of cytokines and inflammatory factors present in the gliotic retina during proliferative vitreoretinopathy. Glia. 2016;64:495-506.

23. Dongre A, Weinberg RA. New insights into the mechanisms of epithelial-mesenchymal transition and implications for cancer. Nat Rev Mol Cell Biol. 2019;20:69-84.

24. Li H, Wang H, Wang F, Gu Q, Xu X. Snail involves in the transforming growth factor beta1-mediated epithelial-mesenchymal transition of retinal pigment epithelial cells. PLoS ONE. 2011;6:e23322.

25. Kimoto K, Nakatsuka K, Matsuo N, Yoshioka H. p38 MAPK mediates the expression of type I collagen induced by TGF-beta 2 in human retinal pigment epithelial cells ARPE-19. Investig Ophthalmol Vis Sci. 2004;45:2431-7.

26. Yokoyama K, Kimoto K, Itoh Y, Nakatsuka K, Matsuo N, Yoshioka H, et al. The PI3K/Akt pathway mediates the expression of type I collagen induced by TGF-beta2 in human retinal pigment epithelial cells. Graefes Arch Clin Exp Ophthalmol. 2012;250:15-23.

27. Kita T, Hata Y, Arita R, Kawahara S, Miura M, Nakao S, et al. Role of TGF-beta in proliferative vitreoretinal diseases and ROCK as a therapeutic target. Proc Natl Acad Sci USA. 2008;105: 17504-9.

28. Chen X, Xiao W, Liu X, Zeng M, Luo L, Wu M, et al. Blockade of Jagged/Notch pathway abrogates transforming growth factor beta2-induced epithelial-mesenchymal transition in human retinal pigment epithelium cells. Curr Mol Med. 2014;14:523-34.

29. Cheng HC, Ho TC, Chen SL, Lai HY, Hong KF, Tsao YP. Troglitazone suppresses transforming growth factor beta-mediated fibrogenesis in retinal pigment epithelial cells. Mol Vis. 2008;14: 95-104.

30. Chen X, Xiao W, Wang W, Luo L, Ye S, Liu Y. The complex interplay between ERK1/2, TGFbeta/Smad, and Jagged/Notch signaling pathways in the regulation of epithelial-mesenchymal transition in retinal pigment epithelium cells. PLoS ONE. 2014;9: e96365.

31. Cui J, Lei H, Samad A, Basavanthappa S, Maberley D, Matsubara $\mathrm{J}$, et al. PDGF receptors are activated in human epiretinal membranes. Exp Eye Res. 2009;88:438-44. 
32. Pennock S, Rheaume MA, Mukai S, Kazlauskas A. A novel strategy to develop therapeutic approaches to prevent proliferative vitreoretinopathy. Am J Pathol. 2011;179:2931-40.

33. Lei H, Velez G, Hovland P, Hirose T, Gilbertson D. Kazlauskas growth factors outside the PDGF family drive experimental PVR. Investig Ophthalmol Vis Sci. 2009;50:3394-403.

34. Lei H, Kazlauskas AJ. Growth factors outside of the plateletderived growth factor (PDGF) family employ reactive oxygen species/Src family kinases to activate PDGF receptor alpha and thereby promote proliferation and survival of cells. Biol Chem. 2009;284:6329-36.

35. Lei H, Rheaume MA, Velez G, Mukai S, Mazlauskas A. Expression of PDGFRalpha is a determinant of the PVR potential of ARPE19 cells. Investig Ophthalmol Vis Sci. 2011;52:5016-21.
36. Rojas J, Fernandez I, Pastor JC, Garcia-Gutierrez MT, Sanabria MR, Brion M, et al. A strong genetic association between the tumor necrosis factor locus and proliferative vitreoretinopathy: the retina 4 project. Ophthalmology. 2010;117:2417.

37. Kon CH, Occleston NL, Aylward GW, Khaw PT. Expression of vitreous cytokines in proliferative vitreoretinopathy:a prospective study. Investig Ophthalmol Vis Sci. 1999;40:705-12.

38. Lashkari K, Rahimi N, Kazlauskas A. Hepatocyte growth factor receptor in human RPE cells: implications in proliferative vitreoretinopathy. Investig Ophthalmol Vis Sci. 1999;40:149-56.

39. Kenarova B, Voinov L, Apostolov C, Vladimirova R, Misheva A. Levels of some cytokines in subretinal fluid in proliferative vitreoretinopathy and rhegmatogenous retinal detachment. Eur $\mathbf{J}$ Ophthalmol. 1997;7:64-67. 